\title{
Editorial
}

\section{Introduction to a New Open-Access Journal by MDPI: Electronic Materials}

\author{
Wojciech Pisula ${ }^{1,2}$ (D) \\ 1 Max Planck Institute for Polymer Research, Ackermannweg 10, 55128 Mainz, Germany; \\ pisula@mpip-mainz.mpg.de \\ 2 Department of Molecular Physics, Faculty of Chemistry, Lodz University of Technology, Zeromskiego 116, \\ 90-924 Lodz, Poland
}

Received: 4 May 2020; Accepted: 4 May 2020; Published: 11 May 2020

check for updates

Electronic materials are ubiquitous and essential for the daily lives of billions of people. We all strongly depend on our communication and computing devices that are basically built with a complex combination of electronic materials. Electronic materials are the basis for the current age of electronics, information, and communication technology, and have been contributing to global economic growth. Electronic materials are integrated into electronic devices for almost all sectors, including information and communication technology, healthcare, manufacturing, automation and control, robotics, process industries, instrumentation, energy and power systems, and defense and security. Because of the great importance of the development of human society, the discovery, progress, and application of new electronic materials has become the focus of academic and industrial research. Modern society is enjoying the rapid development of novel electronic materials for creative and high-tech products and significantly changing our lifestyles and perspectives.

For this reason, I am delighted to introduce the new online open-access journal Electronic Materials. The aim of Electronic Materials is to publish high-quality and high-impact research papers as well as review articles addressing recent advances in fundamental science, engineering, and practical applications of electronic materials. The interdisciplinary topics of the journal include materials science, device engineering, and the physics of electronic and magnetic properties. Electronic Materials also welcomes Special Issue proposals from academics and industrial researchers from all related fields. The Editorial Office, Editorial Board, and I as the Founding Editor-in-Chief encourage scientists and engineers worldwide to publish their innovative ideas and novel cutting-edge developments and technologies in Electronic Materials.

(C) 2020 by the author. Licensee MDPI, Basel, Switzerland. This article is an open access article distributed under the terms and conditions of the Creative Commons Attribution (CC BY) license (http://creativecommons.org/licenses/by/4.0/). 